\title{
Arbuscular Mycorrhizal Fungi Effectively Enhances the Growth of Gleditsia sinensis Lam. Seedlings under Greenhouse Conditions
}

\author{
Jinping Wang ${ }^{1,2}$, Huini Zhong ${ }^{1}$, Lingjun Zhu ${ }^{1}$, Yingdan Yuan ${ }^{1}$, Linhao Xu ${ }^{1}$, G. Geoff Wang ${ }^{2}$, \\ Lu Zhai ${ }^{3}$, Lu Yang ${ }^{1}$ and Jinchi Zhang ${ }^{1, *}$ \\ 1 Co-Innovation Center for Sustainable Forestry in Southern China, Jiangsu Province Key Laboratory of Soil \\ and Water Conservation and Ecological Restoration, Nanjing Forestry University, 159 Longpan Road, \\ Nanjing 210037, China \\ 2 Department of Forestry and Environmental Conservation, Clemson University, Clemson, SC 29634, USA \\ 3 Earth and Environmental Sciences Division, Los Alamos National Laboratory, Los Alamos, NM 87545, USA \\ * Correspondence: zhang8811@njfu.edu.cn; Tel.: +86-854-272-02
}

Received: 10 June 2019; Accepted: 1 July 2019; Published: 9 July 2019

\begin{abstract}
The Chinese honey locust tree Gleditsia sinensis Lam. (Fabaceae) is a precious ecological and economic tree species that has wide-ranging usage. However, knowledge regarding seedling cultivation (especially the use of arbuscular mycorrhizal fungi (AMF)) is scarce, which limits the developent of Gleditsia plantations. A pot experiment was carried out under greenhouse conditions to estimate the effects of three AMF strains (Funneliformis mosseae 1, Funneliformis mosseae 2, and Diversispora tortuosa) on the growth, photosynthetic rate, and nutrient content of $G$. sinensis seedlings. Results showed that the growth parameters (seedling height, basal diameter, dry biomass) of the seedlings were significantly increased by each of the three AMF strains, associated with high root colonization rates (greater than 75\%). Chlorophyll concentrations and photosynthetic rates were also increased by AMF, and phosphorus (P), and potassium (K) content in the three organs (leaf, stem, and root), and nitrogen (N) content in the leaf and stem of arbuscular mycorrhizal (AM) seedlings were significantly higher than in non-AM seedlings. Mycorrhizal dependency of the AM seedlings was greater than $350 \%$, and significantly correlated with the increased $\mathrm{P}$ and $\mathrm{K}$ content in all three organs and increased $\mathrm{N}$ content in the leaf and stem. Positive effects of F. mosseae on growth and the nutrient content of seedlings were higher than those of $D$. tortuosa, but no significant different effects on $G$. sinensis seedlings were observed between the two strains of $F$. mosseae. Hence, growth of G. sinensis seedlings was effectively enhanced by AMF, with F. mosseae being more suitable for the inoculation of $G$. sinensis seedlings. These results indicate that arbuscular mycorrhization is beneficial for the growth of young $G$. sinensis plants. Further research is needed to determine whether the effects can be reproduced in a forest situation.
\end{abstract}

Keywords: arbuscular mycorrhizal fungi; Gleditsia sinensis; growth parameters; nutrient concentrations; mycorrhizal dependency

\section{Introduction}

The genus Gleditsia (Fabaceae) comprises 14 species and is widely distributed in Asia, America, and Africa [1]. Gleditsia species are valuable tree species, in terms of both ecology and economics, and have a wide range of uses. As a shelter forest tree species, they have considerable tolerance to abiotic stresses, such as cold, drought, heat, and salt, as well as resistance to biotic stresses such as pests and pathogens, and can adapt well on the plains and in hill and mountainous areas [2]. The vegetable gum extracted from Gleditsia species can be used in many economic areas, such as the food industry, the mining 
industry, wood processing, and papermaking, and the pod powder has been used in the fermentation of rice straw [3]. Furthermore, Gleditsia species have been widely used for centuries in local and traditional medicine [1]. Today, Gleditsia species have become a research hotspot, with particular focus on the utilization of extracted bioactive compounds from the tissues of Gleditsia species [4,5]. Unfortunately, the increased planting of Gleditsia species has revealed that knowledge of seedling cultivation technique, especially with respect to the use of plant growth-promoting rhizomicroorganisms to aid the cultivation of Gleditsia species, is inadequate.

Among the plant growth-promoting root-associated microorganisms, nitrogen-fixing nodule-forming bacteria and arbuscular mycorrhizal fungi (AMF) are known to be closely associated with optimal establishment and subsequent growth of these leguminous plants [6]. Considerable research has shown that rhizobial bacteria obtain carbon from the leguminous plants and, in return, supply ammonia to the plants by fixing gaseous nitrogen, thus enhancing plant growth $[7,8]$. However, the role of AMF in the growth of leguminous plants has received much less attention. AMF are ubiquitous and ecologically important soil microorganisms that form mutualistic symbioses with the roots of more than $80 \%$ of terrestrial plant species [9]. They are widespread from the tropics to polar regions, from wetlands to arid regions, and can enhance the ability of plants to acquire water and nutrients (in particular, immobile elements such as phosphorous $(\mathrm{P})$ ) and to adapt to stressful conditions, promoting the growth of plants and their adaptability to local environments [10,11]. Research into the positive effects of AMF on the growth of leguminous plants such as soybean (Glycine max) [12], fenugreek (Trigonella foenum-graecum) [13], and pigeon pea (Cajanus cajan) [14], has been reported. However, such research has focused mainly on non-woody crops, and knowledge regarding the effects of AMF on the growth of leguminous tree species is relatively inadequate [14]. So far, no research had been published on the effects of AMF on growth and nutrient uptake of Gleditsia species.

In the current study, we conducted a greenhouse pot experiment to study the effects of three AMF strains on the growth, photosynthesis and nutrient uptake of G. sinensis, under low-P conditions. Our hypothesis was that the AMF could effectively promote the growth of G. sinensis; if successful, our research would increase the efficiency of seedling cultivation of Gleditsia species for use in the development of plantations.

\section{Material and Methods}

\subsection{Plant Seeds, AMF Inocula and Soil}

Seeds of $G$. sinensis were provided by Jiangsu Forestry Station. The seeds were air-dried and their average 1000-grain weights were $181.25 \mathrm{~g}$. All seeds were soaked in $98 \%(\mathrm{w} / \mathrm{v})$ concentrated sulfuric acid for $10 \mathrm{~min}$ to achieve scarification until the color of the seeds had turned to crimson, following which they were washed with sterile distilled water until the $\mathrm{pH}$ value of the residual water on the surface of the seeds was approximately 7.0. After that, the seeds were soaked in distilled water for 2 days. Swollen seeds were pressed into wet yellow sand and placed in a plant incubator in the dark at $25^{\circ} \mathrm{C}$. The wet yellow sand used in the pre-germination stage had been autoclaved at $0.14 \mathrm{MPa}$ and $121{ }^{\circ} \mathrm{C}$ for $2 \mathrm{~h}$ to sterilize it. Germinated seedlings were chosen for experimentation when the shoot reached $5 \mathrm{~cm}$ in length.

F. mosseae 1, F. mosseae 2, and D. tortuosum, used as arbuscular mycorrhizal fungal inoculates, were obtained from the Beijing Academy of Agriculture and Forestry Science. The three inoculates were propagated for three months in sterile yellow sand with maize and clover inter-crops in a controlled-environment climatic chamber $\left(22{ }^{\circ} \mathrm{C}-25{ }^{\circ} \mathrm{C}\right.$ temperature, $60 \%-80 \%$ relative humidity, and 14-h/10-h diurnal light/dark cycles with a photosynthetic photon flux density (PPFD) of $800 \mu \mathrm{mol} \mathrm{m}{ }^{-2} \mathrm{~s}^{-1}$ ). The plants were watered with modified Hoagland's nutrient solution containing only $25 \%$ standard P concentration every week ( $100 \mathrm{~mL}$ per pot). The mycorrhizal inoculates contained yellow sand, infected root fragments, hyphae and spores $(>7 / \mathrm{g})$. 
Nursery substrate consisted of topsoil, yellow sand and vermiculite $(1: 1: 1, \mathrm{v} / \mathrm{v} / \mathrm{v})$. Topsoil was collected from Xiashu Forest Farm of Nanjing Forestry University, and had the following physicochemical properties: total carbon $(\mathrm{C}), 1.55 \%$; total nitrogen $(\mathrm{N}), 0.03 \%$; total $\mathrm{P}, 570.48 \mathrm{mg} \mathrm{kg}^{-1}$; total potassium (K), $15.18 \mathrm{~g} \mathrm{~kg}^{-1}$; available $\mathrm{P}, 10.00 \mathrm{mg} \mathrm{kg}^{-1}$; available $\mathrm{K}, 101.39 \mathrm{mg} \mathrm{kg}^{-1}$; electrical conductivity, $0.23 \mathrm{mS} \mathrm{cm}^{-1}$ (soil:water ratio, 1:5); and $\mathrm{pH}, 7.15$ (soil:water ratio, 1:5). Nursery substrates were autoclaved at $0.14 \mathrm{MPa}$ and $121{ }^{\circ} \mathrm{C}$ for $2 \mathrm{~h}$, and were then placed in the greenhouse of Xiashu Forest Farm for transplanting of the Gleditsia seedlings.

\subsection{Experimental Design}

Four treatments were performed: seedlings inoculated with autoclaved AMF inoculates (control, CK); seedlings inoculated with F. mosseae 1 (FM1); seedlings inoculated with F. mosseae 2 (FM2); seedlings inoculated with $D$. tortuosum (DT). There were three replicates in each treatment, with each replicate comprised of four pots, totaling to 12 pots for each treatment and 48 pots in the experiment. Before transplantation, each pot was sterilized by soaking in $0.3 \% \mathrm{KMnO}_{4}$ solution for $3 \mathrm{~h}$ then washed with tap water. Every pot contained $2.5 \mathrm{~kg}$ of autoclaved nursery substrate and $80 \mathrm{~g}$ of the respective inoculum which was placed $5 \mathrm{~cm}$ beneath the surface of the nursery substrate, and one germinated seedling was transplanted into each pot. The seedlings of $G$. sinensis were grown in the greenhouse from March to September 2018 under the following condition: $18^{\circ} \mathrm{C}-30^{\circ} \mathrm{C}$ temperature, $50 \%-80 \%$ relative humidity, $10-\mathrm{h}$ to 14 -h photoperiod with a photosynthetic photon flux density of about $700-1000 \mu \mathrm{mol} \mathrm{m}{ }^{-2} \mathrm{~s}^{-1}$. Seedlings were watered with modified Hoagland's nutrient solution containing only $25 \%$ standard P concentration ( $300 \mathrm{~mL}$ per pot every time) every month and maintained under optimal moisture conditions to avoid drought stress. The seedlings were harvested at the beginning of September 2018.

\subsection{Seedling Growth Parameters}

At the beginning of July and September 2018, seedling height was measured using a steel ruler before havesting, and basal diameter was measured using a digital caliper at the same time. Then, seedlings were havested from pots. After fresh weights of leaf, stem and root were separated, the three organs were then dried at $105^{\circ} \mathrm{C}$ for $30 \mathrm{~min}$ and at $70^{\circ} \mathrm{C}$ for $48 \mathrm{~h}$ to constant weight, and then weighed. Mycorrhizal dependency (MD) was calculated using the following formula [15]: MD (\%) $=100 \times($ dry weight biomass of inoculated seedlings/dry weight biomass of control seedlings).

\subsection{Root Mycorrhizal Colonization}

Harvested fine roots from each plant were washed and cut into $1 \mathrm{~cm}$ long segments, cleared by soaking in $10 \%(\mathrm{w} / \mathrm{v}) \mathrm{KOH}$ and stained in $0.05 \%(\mathrm{w} / \mathrm{v})$ trypan blue solution [16]. AMF colonization rate was estimated based on the previously described intercept method [17], and calculated using the following formula: root colonization rate $(\%)=$ number of infected root segments/total number of segments $\times 100 \%$.

\subsection{Photosynthetic Pigments and Photosynthetic Rate}

Leaf photosynthetic pigments (Chl, total chlorophyll; $\mathrm{Chl} a$, chlorophyll a; $\mathrm{Chl} b$, chlorophyll b) were extracted with $80 \%$ acetone as described by Zhang et al. [18]. Photosynthetic parameters, including leaf net photosynthetic rate $\left(P_{\mathrm{n}}, \mu \mathrm{mol} \mathrm{CO} \mathrm{m}^{-2} \mathrm{~s}^{-1}\right)$, stomatal conductance $\left(G_{\mathrm{s}}, \mathrm{mmol} \mathrm{m}^{-2} \mathrm{~s}^{-1}\right)$, and transpiration rate $\left(T_{\mathrm{r}}, \mathrm{mmol} \mathrm{H}_{2} \mathrm{O} \mathrm{m}^{-2} \mathrm{~s}^{-1}\right)$, were measured in the third fully expanded leaf using a portable photosynthesis system (LI-6400; LI-COR, Lincoln, NE, USA) during the day of plant harvest between 09:30 and 11:30 prior to harvest [19]. The parameters were determined under the following conditions: photosynthetically active radiation, $1000 \mu \mathrm{mol} \mathrm{m}^{-2} \mathrm{~s}^{-1} ; \mathrm{CO}_{2}$ concentration, $390 \mu \mathrm{mol} \mathrm{mol}{ }^{-1}$; leaf temperature, $25{ }^{\circ} \mathrm{C}$; leaf humidity, $35 \%-50 \%$; and air flow rate, $0.5 \mathrm{dm}^{3} \mathrm{~min}^{-1}$. 


\subsection{Nutrient Contents in Different Organs}

Dried leaves, stems and roots were ground separately and sieved through a $0.5 \mathrm{~mm}$ sieve. Samples of $50 \mathrm{mg}$ were used for the measurement of $\mathrm{N}$ concentration using an elemental analyzer (Vario MACRO cube; Elementar Trading Shanghai, Shanghai, China). Samples of $0.2 \mathrm{~g}$ were digested in an acidic mixture $\left(\mathrm{HClO}_{4}: \mathrm{HNO}_{3}, 1: 5\right)$ and diluted with double-distilled water to determine the concentrations of $\mathrm{P}$ and $\mathrm{K}$. The concentration of $\mathrm{P}$ was determined using the ammonium molybdate blue method in a spectrophotometer (UV 2700, SHIMADZU, Tokyo, Japan), whereas the concentration of $\mathrm{K}$ was determined in an atomic absorption spectrophotometer (AA900T, Perkin Elmer, Norwalk, CA, USA) [20]. Nutrient content $=$ nutrient concentration $\times$ dry weight of organs.

\subsection{Statistical Analysis}

Data were analyzed by analysis of variance (ANOVA), with the means of treatments being compared by pairwise multiple comparisons using Duncan's multiple range test $(p<0.05)$. All data were presented as mean \pm standard deviation and all data analyses were performed using SPSS 19.0 (IBM, Armonk, NY, USA), and graphical presentation of data was carried out using Origin 8.5 (OriginLab, Northampton, MA, USA). The Pearson correlation coefficient was calculated in the R programing language to determine the relationship between mycorrhizal dependency and increased nutrient accumulation in mycorrhized plants.

\section{Results}

\subsection{Mycorrhizal Colonization and Plant Growth Parameters}

The root mycorrhizal colonization status of the four treatments is presented in Figure 1. Hyphae, arbuscules, and vesicles of AMF were observed in the roots of the three inoculation treatments but not in CK. The mycorrhizal colonization rates were 96\%, 97\%, and 79\% in FM1, FM2 and DT, respectively. Seedling heights and basal diameters were significantly increased (relative to the CK) by each of the three AMF strains (Table 1). After about four months, the increased values of seedling heights induced by the FM1, FM2, and DT strains were $29.10 \mathrm{~cm}, 31.59 \mathrm{~cm}$, and $32.47 \mathrm{~cm}$, respectively, relative to the CK, compared with increased values of basal diameters of $1.16 \mathrm{~mm}, 1.30 \mathrm{~mm}$, and $1.03 \mathrm{~mm}$, respectively. After about six months, the increased values of seedling heights induced by the FM1, FM2, and DT strains were $61.33 \mathrm{~cm}, 61.70 \mathrm{~cm}$, and $64.75 \mathrm{~cm}$, respectively, relative to the $C K$, compared with increased values of basal diameters of $2.39 \mathrm{~mm}, 2.60 \mathrm{~mm}$, and $2.32 \mathrm{~mm}$, respectively.

Table 1. Effects of arbuscular mycorrhizal fungi (AMF) on G. sinensis seedling growth, biomass and mycorrhizal dependence.

\begin{tabular}{|c|c|c|c|c|c|c|c|c|}
\hline \multirow{2}{*}{ Treatments } & \multicolumn{2}{|c|}{ Seedling Height $(\mathrm{cm})$} & \multicolumn{2}{|c|}{ Basal Diameter (mm) } & \multicolumn{3}{|c|}{ Dry Weight (g/pot) } & \multirow{2}{*}{$\begin{array}{l}\text { Mycorrhizal } \\
\text { Dependence }\end{array}$} \\
\hline & July & September & July & September & Shoot & Root & Total & \\
\hline CK & $13.24 \pm 2.69 \mathrm{~b}$ & $28.73 \pm 4.82 \mathrm{~b}$ & $2.34 \pm 0.27 \mathrm{~b}$ & $3.11 \pm 0.32 b$ & $3.47 \pm 0.53 b$ & $2.46 \pm 0.31 b$ & $5.92 \pm 0.72 c$ & $0 \pm 0 c$ \\
\hline FM1 & $42.34 \pm 17.16 a$ & $90.06 \pm 18.39 a$ & $3.50 \pm 0.85 a$ & $5.50 \pm 1.40 \mathrm{a}$ & $21.29 \pm 4.60 \mathrm{a}$ & $9.04 \pm 0.63 a$ & $30.33 \pm 4.82 \mathrm{ab}$ & $463.82 \pm 73.78 \mathrm{ab}$ \\
\hline FM2 & $44.83 \pm 12.53 a$ & $90.43 \pm 13.85 a$ & $3.64 \pm 0.61 \mathrm{a}$ & $5.71 \pm 1.27 \mathrm{a}$ & $21.52 \pm 1.65 a$ & $9.52 \pm 1.95 \mathrm{a}$ & $31.04 \pm 0.53 a$ & $474.68 \pm 8.08 \mathrm{a}$ \\
\hline DT & $45.71 \pm 9.15 \mathrm{a}$ & $93.48 \pm 12.44 a$ & $3.37 \pm 0.55 a$ & $5.43 \pm 0.92 a$ & $17.76 \pm 1.56 a$ & $7.67 \pm 1.45 a$ & $25.43 \pm 2.85 b$ & $388.86 \pm 43.55 b$ \\
\hline
\end{tabular}




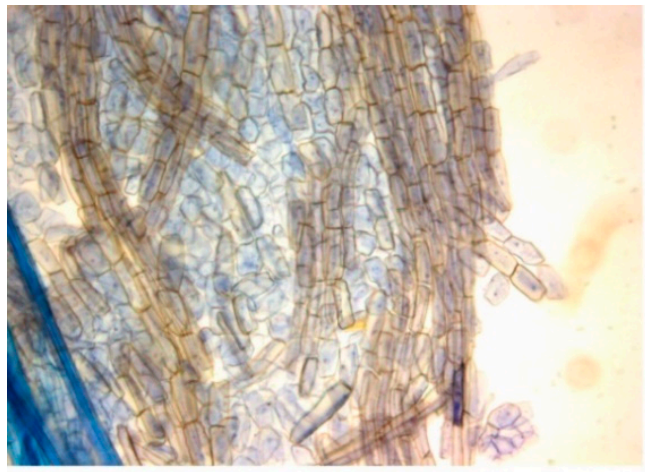

CK colonization rate: $0.00 \%$

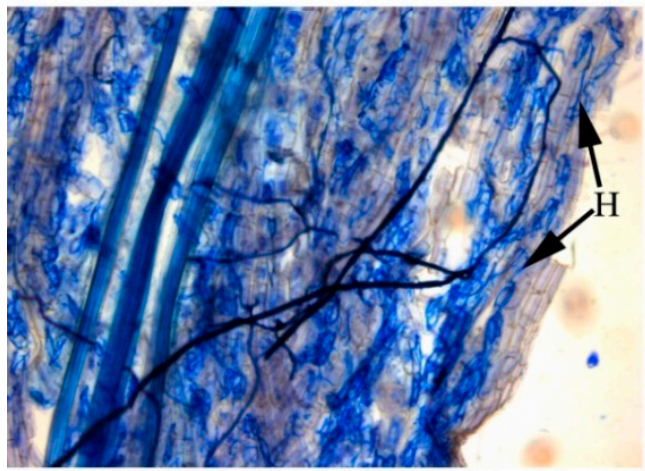

FM2 colonization rate: $97.00 \%$

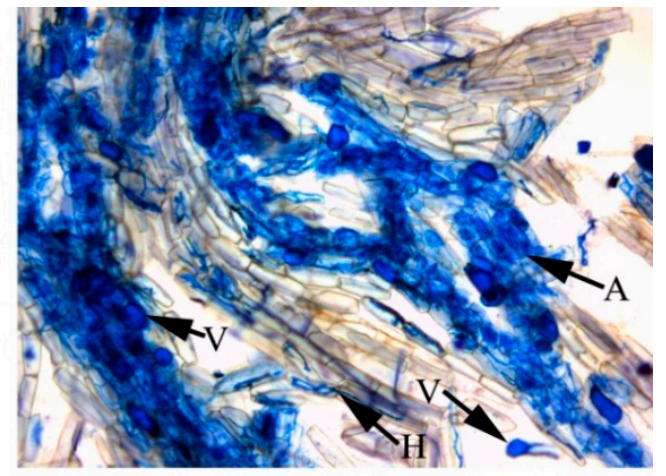

FM1 colonization rate: $96.00 \%$

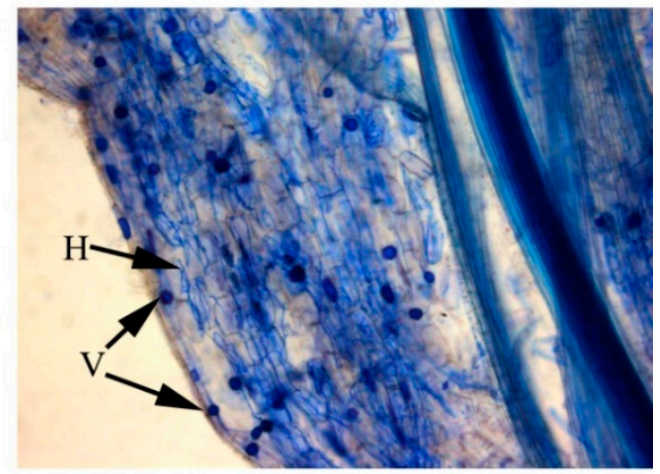

DT colonization rate: $79.00 \%$

Figure 1. Development and colonization rates of arbuscular mycorrhizal fungi in G. sinensis seedling roots. CK-treatment of non-inoculation. FM1-treatment inoculated with F. mosseae 1. FM2 - treatment inoculated with F. mosseae 2. DT-treatment inoculated with D. tortuosum. V-vesicle, $\mathrm{H}-$ hypha, A-arbuscule.

\subsection{Plant Biomass and Mycorrhizal Dependence}

Plant dry biomass was significantly increased by inoculation with AMF (Table 1), and effects of AMF on organs showed the following pattern from high to low: shoot $>$ total $>$ root. After inoculating with FM1, FM2 or DT, the shoot dry weights were increased by $17.82 \mathrm{~g}, 18.08 \mathrm{~g}$, and $14.29 \mathrm{~g}$, respectively, and increases in root dry weights were $6.58 \mathrm{~g}, 7.06 \mathrm{~g}$, and $5.21 \mathrm{~g}$, respectively. Mycorrhizal dependencies exhibited by the three AMF strains were greater than $350 \%$, and were in the order: FM1, FM2 > DT (Table 1).

\subsection{Photosynthetic Pigments and Photosynthesis}

AMF inoculation had positive effects on the concentrations of $\mathrm{Chl}$ a and $\mathrm{Chl}$. The concentration of $\mathrm{Chl}$ a in leaves increased by $0.24 \mathrm{mg} \mathrm{g}^{-1}, 0.28 \mathrm{mg} \mathrm{g}^{-1}$, and $0.22 \mathrm{mg} \mathrm{g}^{-1}$ following inoculation with FM1, FM2 and DT (Table 2). Values of photosynthetic parameters $P_{\mathrm{n}}, G_{\mathrm{s}}$, and $T_{\mathrm{r}}$ were also increased after inoculation with AMF. The values of $P_{\mathrm{n}}$ increased by $1.78 \mu \mathrm{mol} \mathrm{m} \mathrm{m}^{-2} \mathrm{~s}^{-1}, 2.36 \mu \mathrm{mol} \mathrm{m}^{-2} \mathrm{~s}^{-1}$, and $1.38 \mu \mathrm{mol} \mathrm{m}^{-2} \mathrm{~s}^{-1}$, respectively, for the FM1, FM2 and DT treatments, respectively, whereas increased values of $T_{\mathrm{r}}$ were $1.27 \mathrm{mmol} \mathrm{m}^{-2} \mathrm{~s}^{-1}(p<0.05), 1.58 \mathrm{mmol} \mathrm{m}^{-2} \mathrm{~s}^{-1}(p<0.05)$, and $1.28 \mathrm{mmol} \mathrm{m}^{-2} \mathrm{~s}^{-1}$ $(p<0.05)$, respectively. 
Table 2. Effects of arbuscular mycorrhizal fungi on photosynthetic pigments and photosynthesis of $G$. sinensis seedlings.

\begin{tabular}{|c|c|c|c|c|c|c|}
\hline Treatments & Chl a (mg/g) & Chl b (mg/g) & Chl (mg/g) & 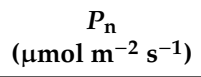 & 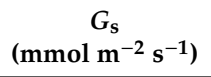 & 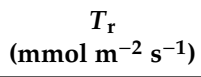 \\
\hline CK & $1.82 \pm 0.40 \mathrm{a}$ & $0.538 \pm 0.206 a$ & $2.35 \pm 0.58 \mathrm{a}$ & $11.54 \pm 2.03 a$ & $0.127 \pm 0.029 a$ & $2.36 \pm 0.37 b$ \\
\hline FM1 & $2.06 \pm 0.29 a$ & $0.446 \pm 0.062 a$ & $2.50 \pm 0.35 a$ & $13.32 \pm 2.95 a$ & $0.132 \pm 0.053 a$ & $3.63 \pm 1.28 \mathrm{a}$ \\
\hline FM2 & $2.10 \pm 0.15 a$ & $0.474 \pm 0.087 \mathrm{a}$ & $2.58 \pm 0.24 a$ & $13.90 \pm 1.88 a$ & $0.169 \pm 0.058 a$ & $3.94 \pm 1.02 \mathrm{a}$ \\
\hline DT & $2.04 \pm 0.17 a$ & $0.416 \pm 0.050 \mathrm{a}$ & $2.46 \pm 0.21 a$ & $12.92 \pm 2.98 \mathrm{a}$ & $0.130 \pm 0.067 a$ & $3.64 \pm 1.47 \mathrm{a}$ \\
\hline
\end{tabular}

CK-treatment of non-inoculation. FM1 — treatment inoculated with F. mosseae 1. FM2-treatment inoculated with F. mosseae 2. DT-treatment inoculated with D. tortuosum. Chl一total chlorophyll. Chl a-chlorophyll a. Chl b-chlorophyll b. $P_{\mathrm{n}}$ - leaf net photosynthetic rate. $G_{\mathrm{s}}$ - stomatal conductance. $T_{\mathrm{r}}$ - transpiration rate. Different lowercase letters indicate significant differences between the three AMF and control treatments.

\subsection{Nitrogen, Phosphorus and Potassium Contents}

$\mathrm{N}, \mathrm{P}$ and $\mathrm{K}$ contents in organs from plants grown under different inoculation treatments were significantly higher than $\mathrm{CK}$ treatments, except for the $\mathrm{N}$ concentrations in stems of the FM1 and DT treatments (Table 3). Percentage increases in P content were higher in the stem and root compared with the leaf for the FM1 and FM2 treatments, but, for the DT treatment, the percentage increase in P content was higher in the leaf and stem than in the root. The percentage increase in P content induced by the three AMF strains showed the following pattern from high to low: FM1 > FM2 > DT. However, the percentage increase in $\mathrm{N}$ and $\mathrm{K}$ content induced by the three AMF strains showed the following pattern from high to low: FM2 > FM1 > DT. Increased N content induced by AMF occurred mainly in the leaf and root, but increased $\mathrm{K}$ concentration was greater in the leaf and stem than in the root. Overall, the positive effects of AMF on the three nutrient elements in the total plant dry biomass showed the following pattern from high to low: $\mathrm{K}>\mathrm{P}>\mathrm{N}$.

Table 3. Effects of arbuscular mycorrhizal fungi on nutrients in different organs.

\begin{tabular}{|c|c|c|c|c|c|c|c|c|}
\hline \multirow{2}{*}{ Nutrient } & \multirow{2}{*}{ Organ } & \multirow{2}{*}{$\frac{\text { CK }}{\text { (mg per pot) }}$} & \multicolumn{2}{|c|}{ FM1 } & \multicolumn{2}{|c|}{ FM2 } & \multicolumn{2}{|c|}{ DT } \\
\hline & & & (mg per pot) & Increase (\%) & (mg per pot) & Increase (\%) & (mg per pot) & Increase (\%) \\
\hline \multirow{4}{*}{$\mathrm{P}$} & Leaf & $2.82 \pm 0.17 b$ & $6.82 \pm 1.58 \mathrm{a}$ & $141.83 \pm 56.16$ & $7.20 \pm 0.81 \mathrm{a}$ & $155.02 \pm 28.67$ & $6.57 \pm 0.64 a$ & $132.98 \pm 22.79$ \\
\hline & Stem & $2.20 \pm 0.24 b$ & $8.20 \pm 1.78 \mathrm{a}$ & $272.88 \pm 81.05$ & $7.27 \pm 0.40 \mathrm{a}$ & $230.52 \pm 18.30$ & $6.81 \pm 0.82 \mathrm{a}$ & $209.42 \pm 37.19$ \\
\hline & Root & $2.37 \pm 0.16 \mathrm{c}$ & $9.95 \pm 1.47 \mathrm{a}$ & $318.95 \pm 62.02$ & $8.78 \pm 1.55 a$ & $269.72 \pm 65.34$ & $4.69 \pm 0.11 \mathrm{~b}$ & $97.386 \pm 4.79$ \\
\hline & Total & $7.40 \pm 0.35 c$ & $24.98 \pm 3.54 a$ & $237.67 \pm 47.79$ & $23.25 \pm 0.75 a$ & $214.30 \pm 10.19$ & $18.07 \pm 1.43 b$ & $144.29 \pm 19.33$ \\
\hline \multirow{4}{*}{$\mathrm{N}$} & Leaf & $41.60 \pm 1.73 b$ & $162.14 \pm 27.56 a$ & $289.80 \pm 66.26$ & $167.53 \pm 15.35 a$ & $302.76 \pm 36.90$ & $149.31 \pm 13.42 a$ & $258.95 \pm 32.25$ \\
\hline & Stem & $75.65 \pm 1.37 \mathrm{~b}$ & $87.88 \pm 18.40 \mathrm{~b}$ & $16.17 \pm 24.32$ & $120.31 \pm 9.55 a$ & $59.04 \pm 12.63$ & $86.17 \pm 10.02 b$ & $13.906 \pm 13.24$ \\
\hline & Root & $50.29 \pm 3.15 b$ & $118.88 \pm 12.82 \mathrm{a}$ & $136.37 \pm 25.49$ & $115.24 \pm 12.81 \mathrm{a}$ & $129.13 \pm 25.47$ & $118.69 \pm 27.11 a$ & $135.99 \pm 53.91$ \\
\hline & Total & $167.54 \pm 3.71 b$ & $368.89 \pm 53.16 a$ & $120.19 \pm 31.73$ & $403.08 \pm 17.34 a$ & $140.59 \pm 10.35$ & $354.16 \pm 41.41 \mathrm{a}$ & $111.39 \pm 24.71$ \\
\hline \multirow{4}{*}{ K } & Leaf & $22.81 \pm 1.08 b$ & $113.20 \pm 21.82 a$ & $396.35 \pm 95.67$ & $126.30 \pm 7.58 a$ & $453.79 \pm 33.24$ & $105.79 \pm 17.12 \mathrm{a}$ & $363.88 \pm 75.08$ \\
\hline & Stem & $16.07 \pm 0.51 b$ & $76.30 \pm 18.83 a$ & $374.80 \pm 117.20$ & $75.49 \pm 7.82 a$ & $369.77 \pm 48.67$ & $55.60 \pm 11.84 a$ & $245.97 \pm 73.70$ \\
\hline & Root & $32.64 \pm 3.52 c$ & $111.06 \pm 7.15 \mathrm{a}$ & $240.23 \pm 21.92$ & $117.81 \pm 12.07 a$ & $260.91 \pm 36.97$ & $88.41 \pm 10.06 b$ & $170.85 \pm 30.81$ \\
\hline & Total & $71.52 \pm 4.01 c$ & $300.56 \pm 44.01 \mathrm{ab}$ & $320.25 \pm 61.54$ & $319.60 \pm 18.67 a$ & $346.88 \pm 26.10$ & $249.80 \pm 27.15 b$ & $249.28 \pm 37.96$ \\
\hline
\end{tabular}

\subsection{Correlation Analysis}

In order to determine how the contribution of AMF to nutrient accumulation affected mycorrhizal dependency, a correlation analysis was conducted (Figure 2). Our data showed that the percentage contribution of AMF to stem $\mathrm{P}$, leaf $\mathrm{N}$, and to leaf, stem and root $\mathrm{K}$ affected mycorrhizal dependency at the 0.01 level, while the percentage contribution of AMF to stem $\mathrm{N}$, and leaf and root $\mathrm{P}$ affected mycorrhizal dependency at the 0.05 level. 


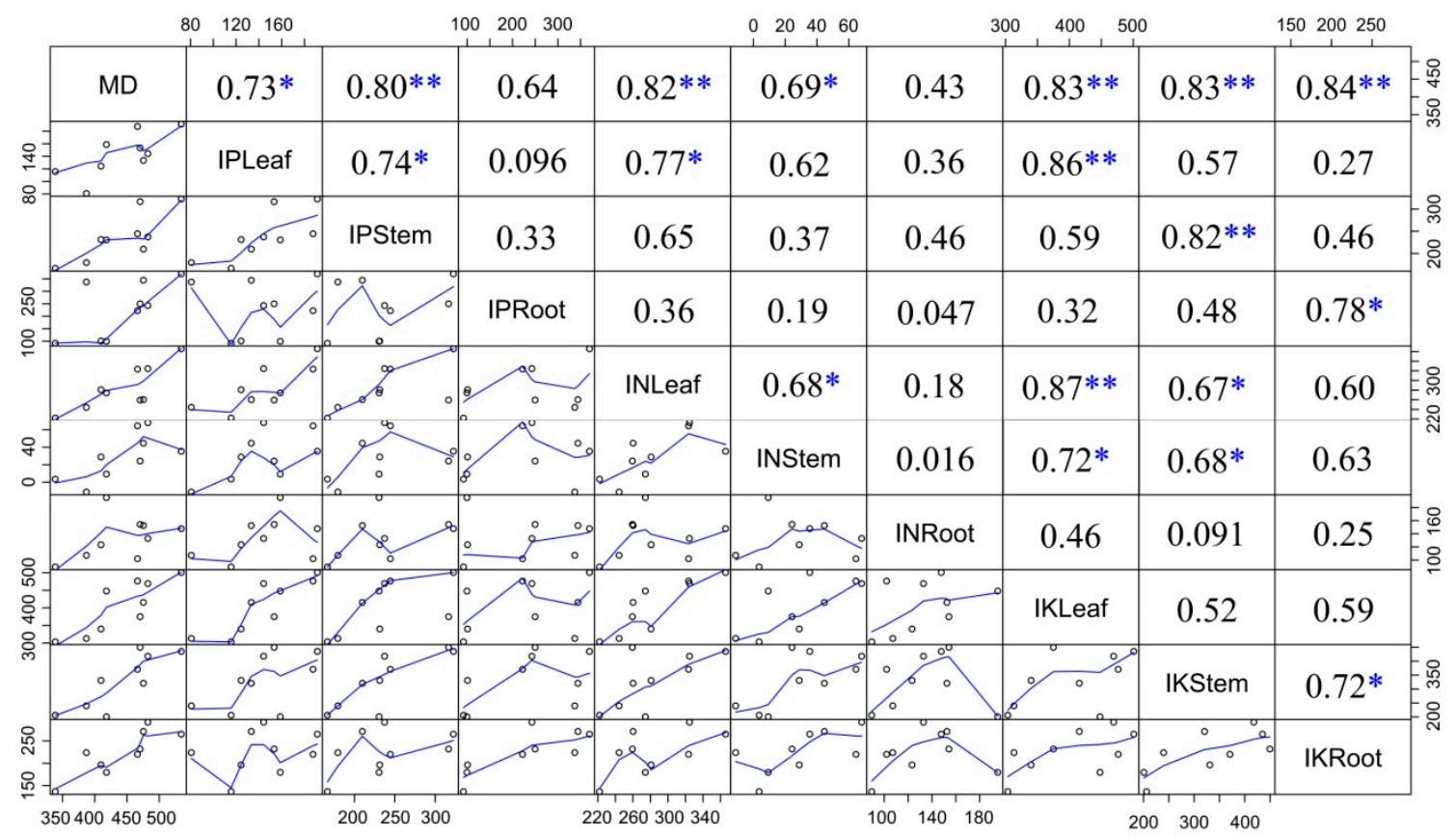

Figure 2. Correlative analysis of mycorrhizal dependence and contribution of AMF on nutrients. MD-mycorrhizal dependency; IPLeaf, IPStem, IPRoot represent the increased P content in the leaf, stem and root; INLeaf, INStem, INRoot represent the increased N content in the leaf, stem and root; IKLeaf, IKStem, IKRoot represent the increased K content in the leaf, stem and root; ${ }^{*} p<0.05,{ }^{* *} p<0.01$.

\section{Discussion}

It is well known that legumes are able to form a mutualistic endosymbiosis with AMF, but the colonization rate varies among different combinations of plants and AMF species [14,21,22]. Our results showed that root colonization rates of the three AMF strains were greater than $70 \%$, with both $F$. mosseae strains resulting in higher colonization rates than $D$. tortuosum, indicating that $G$. sinensis forms a high frequency of mutualistic endosymbioses with AMF, and that $F$. mosseae might be more suitable for root inoculation of $G$. sinensis than D. tortuosum. Data of increased growth (seedling height, basal diameter and biomass) in FM1 and FM2 treatments compared to DT treatment confirmed that F. mosseae was also more effective at improving performance of $G$. sinensis. Similar results had been reported by Zhang et al. who found that growth of Zenia insignis seedlings inoculated with F. mosseae performed better than seedlings inoculated with Rhizoglomus intraradices or Diversisspora versiformis [23].

However, the positive effects of $F$. mosseae on plant growth were not always the best, especially when compared to other AMF species. Zelkova serrata seedlings inoculated with $D$. tortuosum grew better than seedlings inoculated with F. mosseae [19], and the total dry weight of mulberry seedlings inoculated with Rhizoglomus intraradices was $17.56 \%$ higher than that of seedlings inoculated with F. mosseae [24]. These studies indicated that the efficacy of the AMF species depends on the plant species [25]. The occurrence of different ideal combinations of host plant and AMF species are important in maintaining the diversity of plant communities [26]. MD is defined as the degree to which a plant is dependent on the mycorrhizal condition in order to produce its maximum growth or yield at a given level of fertility [27]. Our results showed that mycorrhizal dependency of G. sinensis seedlings inoculated with each of the three AMF strains was greater than $350 \%$, with F. mosseae inoculation resulting in MD values higher than those from D. tortuosum. High MD (greater than $350 \%$ ) was also reported on five citrus rootstocks under low-P sandy soil conditions [15]. The high mycorrhizal dependency values indicated that growth of G. sinensis seedlings was highly dependent on AMF, particularly on F. mosseae compared to D. tortuosum.

Photosynthetic pigments and photosynthetic parameters being enhanced by AMF has been reported by a number of researchers $[12,19]$. Our results showed that $\mathrm{Chl}$ and $\mathrm{Chl}$ a concentrations 
were increased after inoculation with each of the AMF strains. Higher photosynthetic pigment concentrations were associated with greater plant photosynthetic rates, which in turn resulted in greater biomass accumulation.

Macronutrients, especially $\mathrm{P}, \mathrm{N}$, and $\mathrm{K}$, are of vital importance in the growth of plants. Numerous studies have reported that $A M F$ increased nutrient $(\mathrm{P}, \mathrm{N}, \mathrm{K})$ uptake by various plant species under particular conditions [23,28,29]. Mycorrhizae create links between roots and the soil, with the fungal hyphae being functionally analogous to fine root hairs, and acquire nutrients (especially relatively immobile elements such as $\mathrm{P}$ ) by altering the uptake dynamics, whereas mycelia extend the effective absorption surfaces of plant roots [30]. In the present study, P, N, and K contents in seedlings inoculated with AMF were far higher than those in seedlings without AMF, with F. mosseae exerting a greater beneficial effect on the uptake of nutrients (especially P and K) compared to D. tortuosum.

It was interesting to note that the positive effect of AMF species on nutrient content differed markedly between organs. For example, the increase in P content induced by F. mosseae was far higher in the stem and root than in the leaf, but the increased P content induced by D. tortuosum was far higher in the leaf and stem than in the root. Similar results were also presented by Lu et al. [24] who investigated the effects of two AMF species on growth and nutrient content of Morus alba [24]. These findings from the current study indirectly demonstrated that the effects of AMF species on nutrient distribution differed between various organs of the plant. The F. mosseae 1 and F. mosseae 2 strains, isolated from different soil conditions by staff at the Beijing Academy of Agriculture and Forestry Science, showed no significantly different effects on the growth and nutrient concentrations of G. sinensis seedlings. Similar results were also found on $Z$. serrata seedlings [19]. The correlation analysis between mycorrhizal dependency and increased nutrient accumulation indicated that increased biomass by AMF was significantly associated with increased $\mathrm{P}$ and $\mathrm{K}$ content in all three organs, and with $\mathrm{N}$ content in the leaf and stem. Greater biomass reflected a larger root system, which, in turn, increased the amount of $\mathrm{N}, \mathrm{P}$, and $\mathrm{K}$ taken up.

\section{Conclusions}

AMF inoculation significantly increased growth (seedling height, basal diameter and biomass) and nutrient content $(\mathrm{P}, \mathrm{K}$ and $\mathrm{N}$ ) of $\mathrm{G}$. sinensis seedlings, and increased the concentration of photosynthetic pigments and the photosynthetic rate of leaves. Of the AMF species investigated, F. mosseae appeared to be more suitable for the inoculation of G. sinensis seedlings than D. tortuosum.

Author Contributions: J.Z. and J.W. conceived the experiments. J.W., H.Z., L.Z. (Lingjun Zhu), L.X., L.Z. (Lu Zhai), and L.Y conducted the experiments. J.W. and Y.Y. interpreted the data. J.W. wrote the manuscript. G.G.W. revised the manuscript. All authors read and approved the final manuscript.

Funding: This work was financially supported by the Agricultural Science and Technology Independent Innovation Fund of Jiangsu province of China (Grant No. CX (17) 004), the National Special Fund for Forestry Scientific Research in the Public Interest (Grant No. 201504406), the Major Fund for Natural Science of Jiangsu Higher Education Institutions (Grant No. 15KJA220004), the Priority Academic Program Development of Jiangsu Higher Education Institutions (PAPD), and the Doctorate Fellowship Foundation of Nanjing Forestry University (2169125).

Acknowledgments: We thank International Science Editing (http://www.internationalscienceediting.com) for editing this manuscript.

Conflicts of Interest: The authors declare no conflict of interest.

\section{References}

1. Zhang, J.P.; Tian, X.H.; Yang, Y.X.; Liu, Q.X.; Wang, Q.; Chen, L.P.; Li, H.L.; Zhang, W.D. Gleditsia species: An ethnomedical, phytochemical and pharmacological review. J. Ethnopharmacol. 2016, 178, $155-171$. [CrossRef] [PubMed]

2. Lan, Y.P.; Zhou, L.D.; Li, S.Y.; Cao, Q.C.; Lan, W.Z. Advances in research of Gleditsia and its prospect of industrializational development. World For. Res. 2004, 17, 17-21. (In Chinese) 
3. Mei, X.; Ju, L.X.; Fang, C.H.; Li, J.H.; Bi, S.Q.; Chen, Y.; Zou, C.; Zhou, C.; Ma, L.; Miao, L.T. Promoting the hydrolysis and acidification of rice straw by adding Gleditsia sinensis pod powder. Ind. Crops Prod. 2017, 100, 35-40. [CrossRef]

4. Wu, J.; Li, J.; Zhu, Z.; Li, J.; Huang, G.; Tang, Y.; Gao, X. Protective effects of echinocystic acid isolated from Gleditsia sinensis Lam. against acute myocardial ischemia. Fitoterapia 2010, 81, 8-10. [CrossRef]

5. Shaheen, U.; Ragab, E.A.; Abdalla, A.N.; Bader, A. Triterpenoidal saponins from the fruits of Gleditsia caspica with proapoptotic properties. Phytochemistry 2018, 145, 168-178. [CrossRef] [PubMed]

6. Larrainzar, E.; Wienkoop, S. A proteomic view on the role of legume symbiotic interactions. Front. Plant Sci. 2017, 8, 1267. [CrossRef] [PubMed]

7. Qu, L.; Huang, Y.; Zhu, C.; Zeng, H.; Shen, C.; Liu, C.; Zhao, Y.; Pi, E. Rhizobia-inoculation enhances the soybean's tolerance to salt stress. Plant Soil 2016, 400, 209-222. [CrossRef]

8. Gopalakrishnan, S.; Srinivas, V.; Samineni, S. Nitrogen fixation, plant growth and yield enhancements by diazotrophic growth-promoting bacteria in two cultivars of chickpea (Cicer arietinum L.). Biocatal. Agric. Biotechnol. 2017, 11, 116-123. [CrossRef]

9. Pagano, M. Mycorrhiza: Occurrence in Natural and Restored Environments; Nova Science: New York, NY, USA, 2010; pp. 147-163.

10. Marschner, H.; Dell, B. Nutrient uptake in mycorrhizal symbiosis. Plant Soil 1994, 159, 89-102. [CrossRef]

11. Schüßler, A.; Schwarzott, D.; Walker, C. A new fungal phylum, the Glomeromycota: Phylogeny and evolution. Mycol. Res. 2001, 105, 1413-1421. [CrossRef]

12. Bulgarelli, R.G.; Marcos, F.C.C.; Ribeiro, R.V.; der Andrade, S.A.L. Mycorrhizae enhance nitrogen fixation and photosynthesis in phosphorus-starved soybean (Glycine max L. Merrill). Environ. Exp. Bot. 2017, 140, 26-33. [CrossRef]

13. Evelin, H.; Giri, B.; Kapoor, R. Contribution of Glomus intraradices inoculation to nutrient acquisition and mitigation of ionic imbalance in NaCl-stressed Trigonella foenum-graecum. Mycorrhiza 2012, 22, $203-217$. [CrossRef] [PubMed]

14. Garg, N.; Pandey, R. Effectiveness of native and exotic arbuscular mycorrhizal fungi on nutrient uptake and ion homeostasis in salt-stressed Cajanus cajan L. (Millsp.) genotypes. Mycorrhiza 2015, 25, 165-180. [CrossRef] [PubMed]

15. Graham, J.H.; Syvertsen, J.P. Host determinants of mycorrhizal dependency of citrus rootstock seedlings. New Phytol. 2010, 101, 667-676. [CrossRef]

16. Phillips, J.M.; Hayman, D.S. Improved procedures for clearing roots and staining parasitic and vesicular-arbuscular mycorrhizal fungi for rapid assessment of infection. Trans. Br. Mycol. Soc. 1970, 55, 158-161, IN16-IN18. [CrossRef]

17. Biermann, B.; Linderman, R.G. Quantifying vesicular-arbuscular mycorrhizae: A proposed method towards standardization. New Phytol. 1981, 87, 63-67. [CrossRef]

18. Zhang, Q.; Zhang, M.; Ding, Y.; Zhou, P.; Fang, Y.M. Composition of photosynthetic pigments and photosynthetic characteristics in green and yellow sectors of the variegated Aucuba japonica 'Variegata' leaves. Flora 2018, 240, 25-33. [CrossRef]

19. Wang, J.P.; Fu, Z.Y.; Ren, Q.; Zhu, L.J.; Lin, J.; Zhang, J.C.; Cheng, X.F.; Ma, J.Y.; Yue, J.M. Effects of arbuscular mycorrhizal fungi on growth, photosynthesis, and nutrient uptake of Zelkova serrata (Thunb.) Makino seedlings under salt stress. Forests 2019, 10, 186. [CrossRef]

20. Allen, M.F. Mycorrhizae and rehabilitation of disturbed arid soils: Processes and practices. Arid Soil Res. Rehabil. 1989, 3, 229-241. [CrossRef]

21. Giri, B.; Kapoor, R.; Mukerji, K.G. Influence of arbuscular mycorrhizal fungi and salinity on growth, biomass, and mineral nutrition of Acacia auriculiformis. Biol. Fertil. Soils 2003, 38, 170-175. [CrossRef]

22. Giri, B.; Kapoor, R.; Mukerji, K.G. Improved tolerance of Acacia nilotica to salt stress by arbuscular mycorrhiza, Glomus fasciculatum may be partly related to elevated $\mathrm{K} / \mathrm{Na}$ ratios in root and shoot tissues. Microb. Ecol. 2007, 54, 753-760. [CrossRef] [PubMed]

23. Zhang, Z.F.; Zhang, J.C.; Xu, G.P.; Zhou, L.W.; Li, Y.Q. Arbuscular mycorrhizal fungi improve the growth and drought tolerance of Zenia insignis seedlings under drought stress. New For. 2018, 1-12. [CrossRef]

24. Lu, N.; Zhou, X.; Cui, M.; Yu, M.; Zhou, J.X.; Qin, Y.S.; Li, Y. Colonization with arbuscular mycorrhizal fungi promotes the growth of Morus alba L. seedlings under greenhouse conditions. Forests 2015, 6, 734-747. [CrossRef] 
25. Smith, F.A.; Smith, S.E. Mutualism and parasitism: Diversity in function and structure in the "Arbuscular" (VA) mycorrhizal symbiosis. Adv. Bot. Res. 1996, 22, 1-43.

26. Jiang, J.; Moore, J.A.M.; Priyadarshi, A.; Classen, A.T. Plant-mycorrhizal interactions mediate plant community coexistence by altering resource demand. Ecology 2017, 98, 187-197. [CrossRef] [PubMed]

27. Gerdemann, J.W. Vesicular-arbuscular mycorrhizae. In The Development and Function of Roots; Torrey, J.G., Clarkson, D.T., Eds.; Academic Press: London, UK, 1975; pp. 575-591.

28. Lu, Y.W.; Wang, G.Q.; Meng, Q.J.; Zhang, W.H.; Duan, B.L. Growth and physiological responses to arbuscular mycorrhizal fungi and salt stress in dioecious plant Populus tomentosa. Can. J. For. Res. 2014, 44, 1020-1031. [CrossRef]

29. Frosi, G.; Barros, V.A.; Oliveira, M.T.; Santos, M.; Ramos, D.G.; Maia, L.C.; Santos, M.G. Arbuscular mycorrhizal fungi and foliar phosphorus inorganic supply alleviate salt stress effects in physiological attributes, but only arbuscular mycorrhizal fungi increase biomass in woody species of a semiarid environment. Tree Physiol. 2018, 38, 25-36. [CrossRef] [PubMed]

30. Koltai, H.; Kapulnik, Y. Arbuscular Mycorrhizas: Physiology and Function; Springer: Dordrecht, The Netherlands, 2010; pp. 57-71.

(C) 2019 by the authors. Licensee MDPI, Basel, Switzerland. This article is an open access article distributed under the terms and conditions of the Creative Commons Attribution (CC BY) license (http://creativecommons.org/licenses/by/4.0/). 